\title{
Review of Compact and Broadband High Gain Micro Strip Patch Antennas
}

\author{
Shivani Gupta \\ M.Tech Research scholar, Department of \\ Electronics and Communication NIIST Bhopal
}

\begin{abstract}
Generally microstrip patch antenna (MPA) is used in modern communication devices and day-to-day communication is done through it. Study of literature of past few year shows that, the leading work on MPA is design compact size broadband microstrip antenna, but inherently MPA have narrow bandwidth so various techniques are engaged to enhance bandwidth. This review paper demonstrates some commonly engaged techniques with broader-bandwidth since last few decades to fabricate MPA. One of the advantages of microstrip patches over conventional antennas is their small size. However, there are many present day applications where even these small radiators are too large. A microstrip antenna incorporated with a single shorting pin is found to provide reduction in overall area with respect to a conventional patch. The compact circular polarized patch antennas can be achieved by slot loading on patch. In this paper the review on various techniques of compactness by Conductive vias, planar meta-material unit cell and slot loading on microstrip antenna are presented which are reported on literatures.
\end{abstract}

\section{Keywords}

Compact patch,Pin loading, S-shaped impedance matching network with planar meta-material unit cell. Conductive vias.

\section{INTRODUCTION}

Microstrip patch antenna is mostly used because it has many advantages like low cost, compact size, simple structure and compatibility with integrated circuitry. It has many applications in military, radar systems, mobile communications, global positioning system (GPS), remote sensing etc. In this review paper discuss on various techniques of compactness by pin and slot loading on microstrip antenna. A microstrip antenna incorporated with a single shorting post at proper position and size is found to provide reduction in overall area with respect to a conventional patch antenna. Also, the compact Circular polarized patch antennas can be achieved by slot loading on patch. The load of the slots or slits in the radiating patch can cause meandering of the excited patch surface current paths and result in lowering of the resonant frequency of the antenna, which corresponds to a reduced antenna size and compared to a conventional circularly polarized microstrip antenna at the same operating frequency.

The size of the microstrip patch antenna is inversely proportional to the operating frequency of the antenna and the Bandwidth of the microstip patch antenna is directly proportional to the substrate thickness and inversely proportional to the square root of the dielectric constant of the substrate. Mostly low dielectric constant is used because it has a very high water absorption capability. Higher dielectric constants are used in microwave circuits

\author{
Saket Kumar \\ Assistant Prof. \& Guide, Department of Electronics \\ and Communication NIIST Bhopal
}

because they require tightly bounds fields to minimize radiation and coupling and lead to smaller element sizes.

\section{REVIEW OF COMPACT AND BROADBAND}

For design compact and broadband microstrip patch antenna variety of broadband techniques has been developed using the three approaches such as lowering the $\mathrm{Q}$, impedance matching technique and introduce multiple resonances. It is known that the factors affecting the bandwidth of a microstrip patch antenna are primarily the shape of the radiator, the feeding scheme, the substrate and arrangements of radiating and parasitic elements .

In reference papers use many techniques for design compact and broadband microstrip patch antenna such as shorted with a set of conductive vias, meta-material unit cell, S-shaped impedance matching network feed technique and antenna design with radome.

A microstrip patch antenna having a larger sphere suffers from a narrow bandwidth as the whole volume of the enclosing sphere is not utilized effectively. Essentially, the broad bandwidth of a microstrip patch antenna can be attributed to its low $\mathrm{Q}$ value and simultaneously well excited multiple resonances. In lowering the $\mathrm{Q}$ technique firstly reduce the $\mathrm{Q}$ because microstrip patch antenna can be considered as high $-\mathrm{Q}$ circuit then broadens the bandwidth for improving the impedance bandwidth of this antenna use thick substrate with low dielectric constant.

Another technique is Impedance matching in this technique realize good matching between a radiator which has frequency-dependent impedance and a feed structure with constant characteristic impedance. Use two types of method employed in microstrip patch antenna. First is to insert a separate matching network without altering the radiator and second is to introduce an on-patch matching network either by slotting or notching the radiator. With both methods, the insertion of the lossless impedance matching network between the antenna and feeding structure can directly improve the impedance bandwidth. This method has been commonly used in a variety of antenna applications

In multiple resonances technique microstrip patch antennas are structures operating at the resonant frequencies with a very limited bandwidth. For use this technique, two or more adjacent resonances are well excited within the operating frequency range. This technique is mostly used in RF circuits. This technique has been commonly used in $\mathrm{RF}$ circuits such as stage-tuned filters and other antenna applications, such as log-periodic toothed planar antennas and log-periodic dipole arrays. 
Table 1 Broadband techniques for microstrip patch antennas

\begin{tabular}{|c|c|}
\hline Approach & Techniques \\
\hline Lower the Q & $\begin{array}{l}\text { - } \text { Select the radiator shape } \\
\text { - } \text { Thicken the substrate } \\
\text { - } \quad \text { Lower the dielectric constant } \\
\text { - } \quad \text { Increase the losses }\end{array}$ \\
\hline $\begin{array}{l}\text { Using } \\
\text { impedance } \\
\text { matching }\end{array}$ & $\begin{array}{l}\text { - } \\
\text { - } \\
\text { - } \\
\text { - Udd tuning ert a matching netwoments } \\
\text { patches }\end{array}$ \\
\hline $\begin{array}{l}\text { Introduce } \\
\text { multiple } \\
\text { resonances }\end{array}$ & $\begin{array}{l}\text { - Use parasitic (stacked or co- } \\
\text { planar ) elements } \\
\text { - Use slotting patches, insert } \\
\text { impedance networks } \\
\text { - Use an aperture, proximity } \\
\text { coupling }\end{array}$ \\
\hline
\end{tabular}

- Shorted concentrically with a set of conductive vias For design compact and broadband microstrip patch antenna here shorting method used with conductive vias [1] for proposed and analyzed. This type of antenna had wide bandwidth and radiation pattern like a monopole and this antenna was constructed on a circular patch antenna [1] that was shorted concentrically with a set of conductive vias. The antenna was analyzed through cavity model. Here monopolar patch antenna was utilizing two modes $\left(\mathrm{TM}_{01}\right.$ and $\mathrm{TM}_{02}$ modes) and both modes provide monopole like radiation pattern.

In fig 1 assumed radius $r$ of the vias is extremely small and the number of $\mathrm{N}$ of the vias is extremely large. This antenna can provide $18 \%$ bandwidth and maximum gain of $6 \mathrm{~dB}$. So this type of antenna is very simple and is very convenient for design and fabrication.

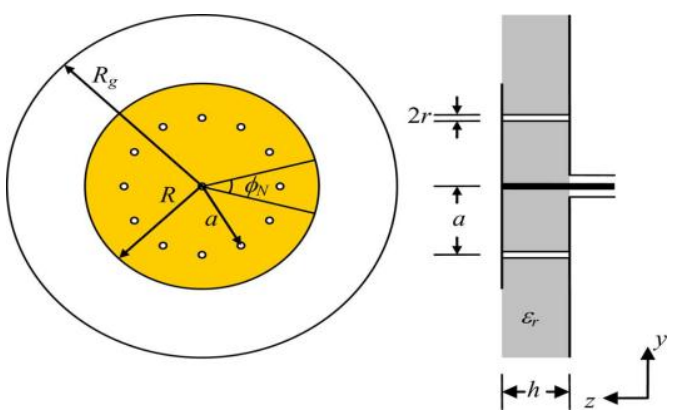

Fig.1 Geometry of the microstrip monopole patch antenna

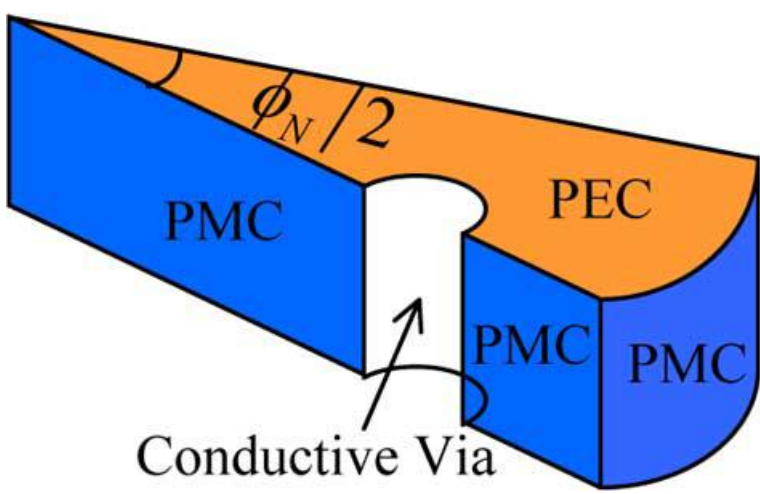

Fig.2 Cavity model for half a sector of the microstrip monopole patch antenna

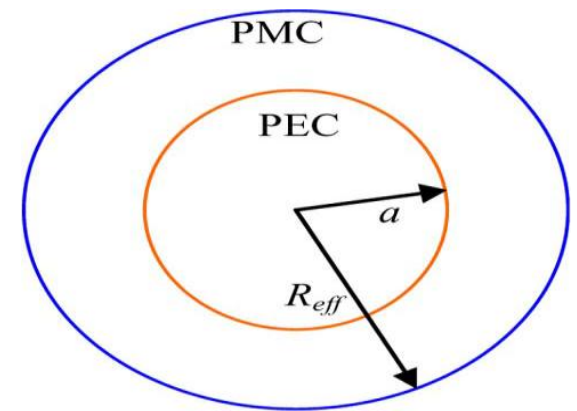

Fig.3 Cavity model for the microstrip antenna shown

- Stack patches with the S-shaped impedance matching network (IMN) feed technique

For design compact and broadband antenna here S-shaped impedance matching network was used [2]. This type of antenna used circular polarization for a mobile $2.45 \mathrm{GHz}$ passive radio frequency identification (RFID) reader. This antenna was consisting two stack patches with the Sshaped impedance matching network (IMN) feed technique. Here good impedance matching and symmetrical broadside radiation patterns had obtained in the antenna. In this antenna used four symmetric-L shaped narrow slots on the patches and obtained compact operation [2]. The peak gain optimized in the frequency range 2.31 to $2.56 \mathrm{GHz}$ which is larger than $6 \mathrm{dBi}$, and achieved $6.32 \mathrm{dBi}$ in the center frequency $2.45 \mathrm{GHz}$ and voltage standing wave ratio $(\mathrm{VSWR})<2$. In this antenna the impedance bandwidth is larger than $15.1 \%$ [2].

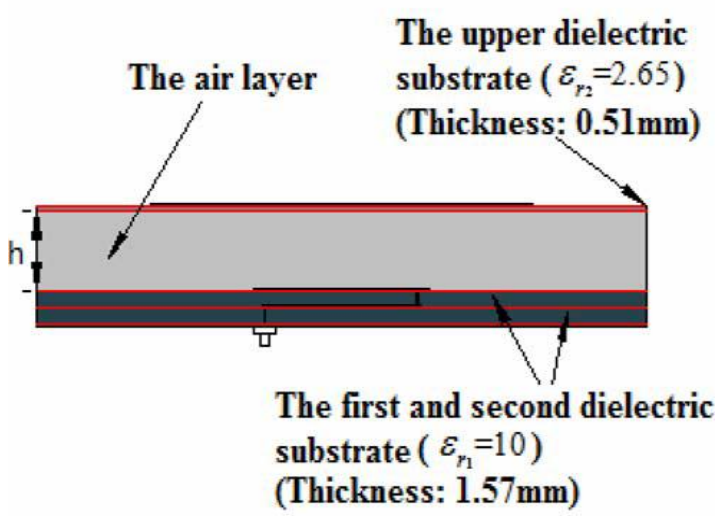

Fig.4(a) Geometry of the proposed compact antenna with circular polarization 


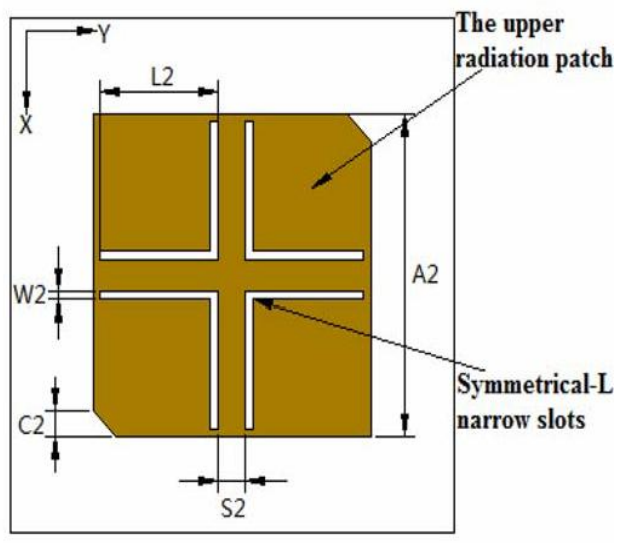

(b) Geometry of the proposed compact antenna with circular polarization

\section{- Meta-Material Unit Cell}

For achieve the wideband patch antenna here metamaterial unit cell technique is used, which was loaded with planar meta-material unit cell [3]. The meta-material unit cell was composed of an inter-digital capacitor and a complementary split-ring resonator (CSRR) slot. In this antenna [3] circulating current distributions around the CSRR slot was used with increased inter-digital finger length bring about the $\mathrm{TM}_{01}$ mode radiation while the normal radiation mode is the $\mathrm{TM}_{10}$. The $\mathrm{TM}_{01}$ mode can be combined with the $\mathrm{TM}_{10}$ mode without a pattern distortion. The dispersion analysis of the meta-material unit cell increase in series capacitance which can decrease the halfwavelength frequency, thus reduce the electrical size of the proposed antenna. The hybridization of the two modes have wideband property $(6.8 \%)$ and unique radiation pattern [3] which was comparable with two independent dipole antennas position orthogonally and these antenna achieves high efficiency (96\%) and reasonable gain (3.85db). This antenna [3] was applicable for a mobile RFID reader system requiring isotropic coverage. The electrical size of the antenna is $0.24 \lambda_{0} \times 0.24 \lambda_{0} \times 0.24 \lambda_{0}$.

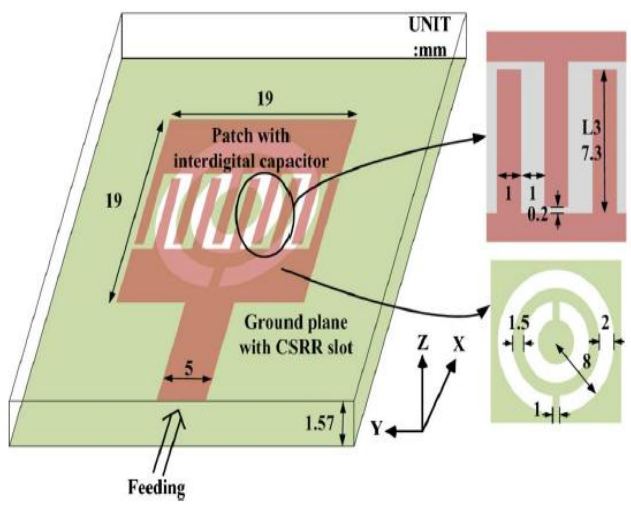

Fig.5 Configuration of the proposed antenna

\section{- Antenna with Radome}

Here Radome was used for design antenna. In this technique discussed about return-loss and the flat gain bandwidth of a micro-strip patch antenna [4] and here radome was used to increase return loss and flat gain bandwidth. Here antenna was randomly consists pair of parallel strips on the bottom of a dielectric material. Pair of strips used for replaces the coupled patch [4]. By adjusting the length of each strip $10 \mathrm{db}$ return loss bandwidth was tuned and the spacing between them [4]. The return-loss and flat gain bandwidths can be optimized with an air thickness of $0.125 \lambda$ between the radome and the patch, this was the advantage of the design. This antenna was dedicated to increase the return-loss bandwidth and gain of microstrip patch antenna. In this antenna a stacked-patches structure was adopted and stacked structure requires a halfwavelength profile to achieve the maximum gain [4].

\section{LITERATURE SURVEY}

An intense survey has been carried out for analysing the radiation characteristics of different microstrip patch antennas. It is presented in tabular for $\mathrm{m}$.

Table 3.1 Literature Survey

\begin{tabular}{|c|c|c|c|c|}
\hline Name of the journal & $\begin{array}{l}\text { shorted } \\
\text { concentrically } \\
\text { with a set of } \\
\text { conductive vias } \\
\qquad 1]\end{array}$ & $\begin{array}{l}\text { Stack patches } \\
\text { and with the S- } \\
\text { shaped } \\
\text { impedance } \\
\text { matching } \\
\text { network (IMN) } \\
\text { feed technique } \\
\quad[2]\end{array}$ & $\begin{array}{l}\text { Meta-Material } \\
\text { Unit Cell } \\
\qquad[3]\end{array}$ & $\begin{array}{c}\text { Antenna with Radome } \\
\qquad[4]\end{array}$ \\
\hline Dielectric Sub. & RT- Duroid5870 & $\begin{array}{c}\text { FR-4, RT-Duroid } \\
5870\end{array}$ & Meta-material & FR-4 \\
\hline Frequency & $2.26 \mathrm{GHz}$ & 2.31 to $2.56 \mathrm{GHz}$ & $3.80 \mathrm{GHz}$ & $2.5 \mathrm{GHz}$ \\
\hline Efficiency & 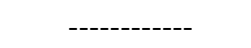 & $87 \%$ & $96 \%$ & ------------- \\
\hline
\end{tabular}




\begin{tabular}{|l|c|c|c|c|}
\hline Feeding Method & $\begin{array}{c}\text { Coaxial } \\
\text { transmission line }\end{array}$ & $\begin{array}{c}\text { S-Shaped } \\
\text { impedance } \\
\text { matching network }\end{array}$ & $\begin{array}{c}\text { Coaxial transmission } \\
\text { line }\end{array}$ & Coaxial feed \\
\hline Gain & $6 \mathrm{dBi}$ & $6.32 \mathrm{dBi}$ & $3.85 \mathrm{dBi}$ & 2.39 to $2.62 \mathrm{GHz}(9.2 \%)$ \\
\hline Bandwidth & $\begin{array}{c}2.06 \text { to } 2.46 \mathrm{GHz} \\
(18 \%)\end{array}$ & $15.1 \%$ & 3.67 to $3.93 \mathrm{GHz}(6.8 \%)$ & $-22 \mathrm{Db}$ \\
\hline Return loss & $-55 \mathrm{Db}$ & $-24 \mathrm{Db}$ & $-25 \mathrm{~dB}$ & 1.127 \\
\hline VSWR & 1.00 & 1.079 & 1.0634 & \\
\hline
\end{tabular}

\section{CONCLUSION}

From this review, it is understood that many efforts are going on to overcome some of the limitations of conventional microstrip antenna characteristics. This review work is done on some certain critical issues like compactness implemented through different techniques. Nevertheless, as regards this issue, useful solutions are still few in number and the solutions often suffer from other problems like distortion of radiation patterns, complexity of structure, reduction of gain etc. Hence, the author feels that further research is seriously needed in these areas.

\section{REFRENCES}

[1] Design and Analysis of a Low-Profile and Broadband Microstrip Monopolar Patch Antenna. Progress in Transactions On Antennas and propagation. VOL. 61, NO. 1, pp 11-18, JAN

[2] Compact and broadband Micro strip stacked Patch Antenna with Circular polarization for $2.45 \mathrm{GHz}$ Mobile RFID Reader. Applied Antenna and Wireless Propagation Letters Vol2, pp623-626, 2013

[3] Hybrid Mode Wideband Patch Antenna Loaded With a Planar Meta-material Unit Cell Jaegeun Ha, Kyeol Kwon, Youngki Lee, and Jaehoon Choi. Progress in Transactions On Antennas and propagation. VOL.60, NO. 2, pp 1143-1147, FEBRUARY 2012

[4] Enhances Return- Loss and Flat-Gain Bandwidth for Micro strip Patch Antenna. The- Nan Chang and Jyun-Ming Lin. Progress in Transactions On Antennas and propagation. VOL.59, NO. 11, pp 4322-4325, NOVEMBER 2011.

[5] Broadband and Design of Circularly Polarized Micro strip Patch Antenna Using Artificial
Ground Structure with Rectangular Unit Cells, International Journal of Transaction on Antennas and Propagation, Vol.59, NO 6, pp 2103-2110, May-June 2011

[6] A compact micro strip patch antenna for wireless communication. U Chakraborty, S Chatterjee, S. K. Choudhry. Progress in Electromagnetic Research (PIER) M, Vol.18, pp 211-220, 2011.

[7] Determination of dielectric constant of fabric materials and their use as substrates for design and development of antennas for wearable applications. S. Sankarlingam, Sr. member, IEEE. IEEE Transactions on instrumentation and measurement, Vol. 59, Issue 12, Dec 2010.

[8] New Multiband E-Shape Microstrip Patch Antenna On RT DUROID 5880 Substrate and RO4003 Substrate for Pervasive Wireless Communication. Dr. Anubhuti Khare, Rajesh Nema and Puran Gour, International Journal of Computer Application (IJCA), Vol.9, Issue 8, Nov. 2010

[9] Design of Circular microstrip antenna. N.A Zakaria, A.A. Sulaiman and M.A.A. Latip, IEEE International $\mathrm{RF}$ and Microwave conference proceedings, Kuala lumpur, Malaysia.,Dec 24,2008.

[10] Equilateral triangular micro strip antenna for circular polarization dual-band operation. Rajesh K. Vishwakarma, J A Ansari and M.K. Meshram. Indian Journal of Radio and Space Physics (IJRSP), Vol.35, pp 293-296, Aug 2006.

[11] D. Guha and J.Y. Siddiqui, "Resonant frequency of circular microstrip antenna covered with dielectric superstreet. IEEE Trans. Antennas Propagate., vol. 51, no.7, pp.1649-16 